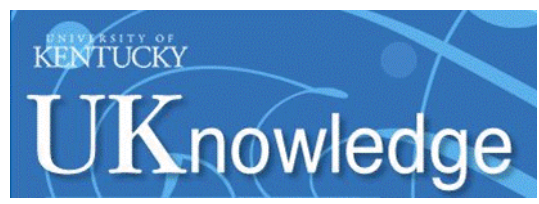

University of Kentucky

UKnowledge

\title{
Characteristics of Clinical Shoulder Research Over the Last Decade: A Review of Shoulder Articles in The Journal of Bone \& Joint Surgery from 2004 to 2014
}

\author{
Gary M. Gartsman \\ Texas Orthopedic Hospital \\ Brent J. Morris \\ Shoulder Center of Kentucky \\ R. Zackary Unger \\ University of Kentucky, zack.unger@uky.edu \\ Mitzi S. Laughlin \\ University of Houston \\ Hussein A. Elkousy \\ Texas Orthopedic Hospital \\ Follow this and additional works at: https://uknowledge.uky.edu/orthopaedicsurgery_facpub \\ Ia next page for additional authors \\ Part of the Orthopedics Commons, and the Sports Sciences Commons \\ Right click to open a feedback form in a new tab to let us know how this document benefits you.
}

\section{Repository Citation}

Gartsman, Gary M.; Morris, Brent J.; Unger, R. Zackary; Laughlin, Mitzi S.; Elkousy, Hussein A.; and Edwards, T. Bradley, "Characteristics of Clinical Shoulder Research Over the Last Decade: A Review of Shoulder Articles in The Journal of Bone \& Joint Surgery from 2004 to 2014" (2015). Orthopaedic Surgery and Sports Medicine Faculty Publications. 8.

https://uknowledge.uky.edu/orthopaedicsurgery_facpub/8

This Article is brought to you for free and open access by the Orthopaedic Surgery and Sports Medicine at UKnowledge. It has been accepted for inclusion in Orthopaedic Surgery and Sports Medicine Faculty Publications by an authorized administrator of UKnowledge. For more information, please contact UKnowledge@lsv.uky.edu. 


\section{Characteristics of Clinical Shoulder Research Over the Last Decade: A Review of Shoulder Articles in The Journal of Bone \& Joint Surgery from 2004 to 2014}

Digital Object Identifier (DOI)

http://dx.doi.org/10.2106/JBJS.N.00831

\section{Notes/Citation Information}

Published in The Journal of Bone \& Joint Surgery, v. 97, no. 5, article e26, p. 1-8.

Copyright $\odot 2015$ by The Journal of Bone and Joint Surgery, Incorporated

The copyright holders have granted the permission for posting the article here.

\section{Authors}

Gary M. Gartsman, Brent J. Morris, R. Zackary Unger, Mitzi S. Laughlin, Hussein A. Elkousy, and T. Bradley Edwards 


\section{ORTHOPAEDIC FORUM}

\section{Characteristics of Clinical Shoulder Research Over the Last Decade: A Review of Shoulder Articles in The Journal of Bone \& Joint Surgery from 2004 to 2014}

Gary M. Gartsman, MD, Brent J. Morris, MD, R. Zackary Unger, MD, Mitzi S. Laughlin, PhD, Hussein A. Elkousy, MD, and T. Bradley Edwards, MD

Background: The purpose of this study was to determine characteristics and trends in published shoulder research over the last decade in a leading orthopaedic journal.

Methods: We examined all clinical shoulder articles published in The Journal of Bone \& Joint Surgery from 2004 to 2014. The number of citations, authorship, academic degrees of the authors, country and institution of origin, topic, level of evidence, positive or nonpositive outcome, and inclusion of validated patient-reported outcome measures were assessed for each article.

Results: Shoulder articles that included an author with an advanced research degree (MD [Doctor of Medicine] with a $\mathrm{PhD}$ [Doctor of Philosophy] or other advanced degree) increased during the study period ( $\mathrm{p}=0.047)$. Level-I, II, and III studies were more likely to have an author with an advanced research degree, and Level-IV studies were more likely to have MDs only $(p=0.03)$. Overall, there was great variability of outcome measures, with at least thirty-nine different validated or nonvalidated outcome measures reported.

Conclusions: Over the last decade, there was an improvement in the level of evidence of shoulder articles published in The Journal of Bone \& Joint Surgery that corresponds with recent emphasis on evidence-based medicine. A consensus is needed in shoulder research for more consistent application of validated patient-reported outcome measurement tools.

Peer Review: This article was reviewed by the Editor-in-Chief and one Deputy Editor, and it underwent blinded review by two or more outside experts. The Deputy Editor reviewed each revision of the article, and it underwent a final review by the Editor-in-Chief prior to publication. Final corrections and clarifications occurred during one or more exchanges between the author(s) and copyeditors.

Disclosure: None of the authors received payments or services, either directly or indirectly (i.e., via his or her institution), from a third party in support of any aspect of this work. One or more of the authors, or his or her institution, has had a financial relationship, in the thirty-six months prior to submission of this work, with an entity in the biomedical arena that could be perceived to influence or have the potential to influence what is written in this work. No author has had any other relationships, or has engaged in any other activities, that could be perceived to influence or have the potential to influence what is written in this work. The complete Disclosures of Potential Conflicts of Interest submitted by authors are always provided with the online version of the article. 
The Journal of Bone \& Joint Surgery - jbjs.org Volume 97-A • Number $5 \cdot$ March 4, 2015
Characteristics of Clinical Shoulder Research in JBjS

Over the Past Decade
There have been several trends in orthopaedic research publications. Authorship proliferation in publications has occurred with more authors per article along with an increase in the proportion of nonclinician scientists ${ }^{1,2}$. The level of evidence has also improved ${ }^{3,4}$. Geographic diversity has increased, with more publications from countries outside of the United States ${ }^{2,4}$ and more multinational collaboration ${ }^{2}$. There has also been concern that publication bias exists in orthopaedic journals toward positive-outcome studies ${ }^{5,6}$. To our knowledge, no information has assessed whether these trends apply to shoulder research, and a critical assessment of the characteristics and trends of clinical shoulder research has not been published.

\section{Materials and Methods}

We completed a PubMed search (http://www.ncbi.nlm.nih.gov/pubmed) of all The Journal of Bone \& Joint Surgery (JBJS) publications over a ten-year period,

TABLE I Top Ten Most-Cited Articles on Thomson Reuters Web of Science with Authors and Country of Origin

\begin{tabular}{|c|c|c|c|c|c|c|}
\hline Year & Article & $\begin{array}{l}\text { No. of } \\
\text { Citations }\end{array}$ & $\begin{array}{l}\text { Overall } \\
\text { JBJS } \\
\text { Citation } \\
\text { Ranking }\end{array}$ & First Author & Last Author & $\begin{array}{l}\text { Country of } \\
\text { Origin }\end{array}$ \\
\hline 2004 & $\begin{array}{l}\text { The Outcome and Repair Integrity } \\
\text { of Completely Arthroscopically } \\
\text { Repaired Large and Massive } \\
\text { Rotator Cuff Tears }{ }^{11}\end{array}$ & 495 (45/yr) & 3 & Galatz, Leesa & Yamaguchi, Ken & United States \\
\hline 2005 & $\begin{array}{l}\text { Treatment of Painful } \\
\text { Pseudoparesis Due to Irreparable } \\
\text { Rotator Cuff Dysfunction with the } \\
\text { Delta III Reverse-Ball-and-Socket } \\
\text { Total Shoulder Prosthesis }{ }^{18}\end{array}$ & $214(21.4 / y r)$ & 14 & Werner, Clement & Gerber, Christian & Switzerland \\
\hline 2006 & $\begin{array}{l}\text { Risk Factors for Recurrence of } \\
\text { Shoulder Instability After } \\
\text { Arthroscopic Bankart Repair }\end{array}$ & 180 (20/yr) & 26 & Boileau, Pascal & Neyton, Lionel & France \\
\hline 2005 & $\begin{array}{l}\text { The Reverse Shoulder Prosthesis } \\
\text { for Glenohumeral Arthritis } \\
\text { Associated with Severe Rotator } \\
\text { Cuff Deficiency: A Minimum Two- } \\
\text { Year Follow-up Study of Sixty } \\
\text { Patients }\end{array}$ & 169 (16.9/yr) & 28 (tie) & Frankle, Mark & Vasey, Matthew & United States \\
\hline 2007 & $\begin{array}{l}\text { Reverse Total Shoulder } \\
\text { Arthroplasty: A Review of Results } \\
\text { According to Etiology }{ }^{24}\end{array}$ & 151 (18.9/yr) & 42 (tie) & Wall, Bryan & Walch, Gilles & France \\
\hline 2006 & $\begin{array}{l}\text { Reverse Total Shoulder } \\
\text { Arthroplasty: Survivorship Analysis } \\
\text { of Eighty Replacements Followed } \\
\text { for Five to Ten Years }{ }^{25}\end{array}$ & $151(16.8 / y r)$ & 42 (tie) & Guery, Jacques & Walch, Gilles & France \\
\hline
\end{tabular}




\begin{tabular}{|c|c|c|c|c|c|}
\hline Year & Article & No. of Citations & First Author & Last Author & $\begin{array}{l}\text { Country of } \\
\text { Origin }\end{array}$ \\
\hline 2004 & $\begin{array}{l}\text { The Outcome and Repair Integrity of } \\
\text { Completely Arthroscopically Repaired } \\
\text { Large and Massive Rotator Cuff Tears }\end{array}$ & 786 (71.5/yr) & Galatz, Leesa & Yamaguchi, Ken & United States \\
\hline 2005 & $\begin{array}{l}\text { Arthroscopic Repair of Full-Thickness } \\
\text { Tears of the Supraspinatus: Does the } \\
\text { Tendon Really Heal? }^{17}\end{array}$ & 477 (47.7/yr) & Boileau, Pascal & Krishnan, Sumant & France \\
\hline 2005 & $\begin{array}{l}\text { Treatment of Painful Pseudoparesis Due } \\
\text { to Irreparable Rotator Cuff Dysfunction } \\
\text { with the Delta III Reverse-Ball-and-Socket } \\
\text { Total Shoulder Prosthesis }\end{array}$ & 408 (40.8/yr) & Werner, Clement & Gerber, Christian & Switzerland \\
\hline 2005 & $\begin{array}{l}\text { The Reverse Shoulder Prosthesis for } \\
\text { Glenohumeral Arthritis Associated with } \\
\text { Severe Rotator Cuff Deficiency: A Mini- } \\
\text { mum Two-Year Follow-up Study of Sixty } \\
\text { Patients }\end{array}$ & 362 (36.2/yr) & Frankle, Mark & Vasey, Matthew & United States \\
\hline 2007 & $\begin{array}{l}\text { Repair Integrity and Functional Outcome } \\
\text { After Arthroscopic Double-Row Rotator } \\
\text { Cuff Repair: A Prospective Outcome } \\
\text { Study }^{23}\end{array}$ & 304 (38.0/yr) & Sugaya, Hiroyuki & Moriishi, Joji & Japan \\
\hline 2006 & $\begin{array}{l}\text { Latissimus Dorsi Transfer for the } \\
\text { Treatment of Irreparable Rotator Cuff } \\
\text { Tears }^{26}\end{array}$ & 303 (33.7/yr) & Gerber, Christian & Espinosa, Norman & Switzerland \\
\hline
\end{tabular}

between January 1, 2004, and December 31, 2013, using the key word shoulder. The PubMed search (completed on January 6, 2014) yielded 575 articles. We completed a separate search on the JBJS web site (http://jbjs.org) (January 6, 2014) under the "Browse by" feature using Shoulder, which yielded 546 articles. A single reviewer (B.J.M.) excluded duplicates and screened all titles and abstracts to determine eligibility. All scientific articles and Evidence-Based Orthopaedics articles were evaluated for inclusion. Exclusion criteria included cadaveric and computer-modeling studies, basic science articles (in vitro studies and nonhuman studies), pediatric studies (studies focused on patients younger than eighteen years of age), articles on clavicle and humeral shaft fractures, and articles from selected Instructional Course Lectures, Case Reports, Current Concepts Reviews, The Orthopaedic Forums, Topics in Training, Specialty Updates, Commentary and Perspectives, Editorials, Ethics in Practice, Surgical Techniques, JBJS Classics, Expressions of Concern, and Book Reviews. A total of 347 articles were excluded, leaving 228 clinical shoulder articles of the 575 articles that met the inclusion criteria. Among the 347 excluded articles were Current Concepts Reviews, Instructional Course Lectures, and reviews (sixty-one articles); articles on cadavers and computer modeling and simulation (forty-six articles); commen- taries and author replies (forty-six articles); case reports (thirty-three articles); basic science articles (nine articles); articles on the clavicle, elbow, forearm, wrist, hand, spine, and lower extremity (ninety-nine articles); articles on surgical techniques (thirty articles); and other articles (twenty-three articles).

The articles were assessed by title, year of publication, number of citations (as determined by Thomson Reuters Web of Science and Google Scholar), authorship, academic degrees of the authors, country and institution of origin (including academic or private institution), shoulder topic, level of evidence, positive or nonpositive outcome, and inclusion of patient-reported outcome measurement tools. Two authors (B.J.M. and R.Z.U.) reviewed all 228 eligible articles, and the senior author (G.M.G.) served as a third reviewer and referee for any disagreements.

Determination of the number of citations per article was completed with use of Thomson Reuters Web of Science, a proprietary product ${ }^{7}$. We also determined the number of citations per article with use of Google Scholar (http://scholar.google.com) for comparison. The number of citations was only determined for articles from 2004 through 2011. Articles from 2012 and 2013 were excluded from citation calculations because of the low likelihood of being cited in such a short time period given the publication lag. 
The Journal of Bone \& Joint Surgery $\cdot$ Jbjs.org Volume 97-A - Number 5 - March 4, 2015
Characteristics of Clinical Shoulder Research in JBjS Over the Past Decade

\begin{tabular}{|cll|}
\hline \multicolumn{2}{|c|}{$\begin{array}{c}\text { TABLE III Top Ten (Including Ties) Most-Published First } \\
\text { Authors } \text { and Countries of Origin }\end{array}$} \\
$\begin{array}{c}\text { No. of } \\
\text { Publications }\end{array}$ & \multicolumn{1}{|c|}{ First Author } & Country of Origin \\
\hline Seven & Robinson, C. Michael & United Kingdom \\
Four & Boileau, Pascal & France \\
Four & Gerber, Christian & Switzerland \\
Four & Namdari, Surena & United States \\
Four & Wirth, Michael & United States \\
Three & Cuff, Derek J. & United States \\
Three & Henn III, R. Frank & United States \\
Three & lannotti, Joseph & United States \\
Three & Kim, Kyung Cheon & South Korea \\
Three & Kim, H. Mike & United States \\
Three & Scalise, Jason J. & United States \\
Three & Tashjian, Robert & United States \\
\hline
\end{tabular}

TABLE IV Top Ten (Including Ties) Most-Published Last Author and Country of Origin

\begin{tabular}{|c|c|c|}
\hline $\begin{array}{c}\text { No. of } \\
\text { Publications }\end{array}$ & Last Author & $\begin{array}{l}\text { Country of } \\
\text { Origin }\end{array}$ \\
\hline Eleven & Matsen III, Frederick A. & United States \\
\hline Ten & Gerber, Christian & Switzerland \\
\hline Nine & Cofield, Robert & United States \\
\hline Nine & Yamaguchi, Ken & United States \\
\hline Seven & lannotti, Joseph & United States \\
\hline Six & Frankle, Mark & United States \\
\hline Six & Warner, Jon J.P. & United States \\
\hline Five & Green, Andrew & United States \\
\hline Five & Walch, Gilles & France \\
\hline Four & McFarland, Edward G. & United States \\
\hline Four & Murrell, George A.C. & Australia \\
\hline
\end{tabular}

We determined each author's educational background with use of previously described methods ${ }^{2}$. All degree classifications were converted to American degree equivalents, and Doctor of Osteopathy (DO) degrees were treated as MD (Doctor of Medicine) degrees ${ }^{2}$. Each author was categorized as a clinician only (MD without an advanced research degree), a clinician scientist (MD with an advanced degree such as an MPH [Master of Public Health], MSci [Master of Science], PhD [Doctor of Philosophy], or MBA [Master of Business Administration]), a nonclinician scientist ( $\mathrm{PhD}$ without an $\mathrm{MD}$ or $\mathrm{DO})$, or others.

The level of evidence for each article was determined by JBJS at the time of publication. The level of evidence has been included for JBJS articles since $2003^{8}$. The evaluation of positive or nonpositive conclusions was based on previously described methods ${ }^{9}$. A positive study was one with a conclusion that favored the experimental method in the study over the standard of care. A negative study was one with a conclusion that favored against the experimental method compared with the standard of care. A neutral study made no judgment, either positive or negative, or found no difference between the experi- mental method and the standard of care. Negative and neutral findings were considered together for calculations and were referred to as nonpositive.

Patient-reported outcome measurement tools were assessed for studies evaluating clinical outcomes. Radiographic studies and short-term diagnostic studies were not considered eligible for evaluation of patient-reported outcomes. We identified 167 of 228 articles that were eligible for inclusion of patient-reported outcomes. The determination of validated or nonvalidated outcome measures was determined by prior publications that were completed to determine validity of the scoring system ${ }^{10}$.

\section{Statistical Analysis}

All analyses were based on yearly totals for number of authors, academic degrees of the authors, level of evidence, and positive results reporting bias. Chisquare tests were utilized to determine whether count data differed between publication years. The significance level was set a priori at $\mathrm{p}<0.05$.

\section{Source of Funding}

There was no external funding source for this investigation.

\section{Results}

\section{Most-Cited Articles}

A total of 228 eligible shoulder articles were identified among 575 articles. The top ten most-cited articles in the last decade according to Web of Science were highlighted (Table I). The most-cited article, by Galatz et al. ${ }^{11}$, "The Outcome and Repair Integrity of Completely Arthroscopically Repaired Large and Massive Rotator Cuff Tears," was cited 495 times according to Web of Science (forty-five citations per year) and was the third most-cited study among all JBJS articles in the last decade.

The top-ten list for most-cited articles according to Web of Science was compared with the top-ten list for citations according to Google Scholar (Table II). The top-ten lists matched on nine of the top ten articles. The average number of citations for all articles published from 2004 through 2011 was 40.2 per article according to Web of Science compared with 78.3 per article according to Google Scholar.

\section{Manuscripts by Number of Authors per Year}

\section{1 to 2 authors $\square 3$ to 5 authors $\quad \square 6$ + authors}

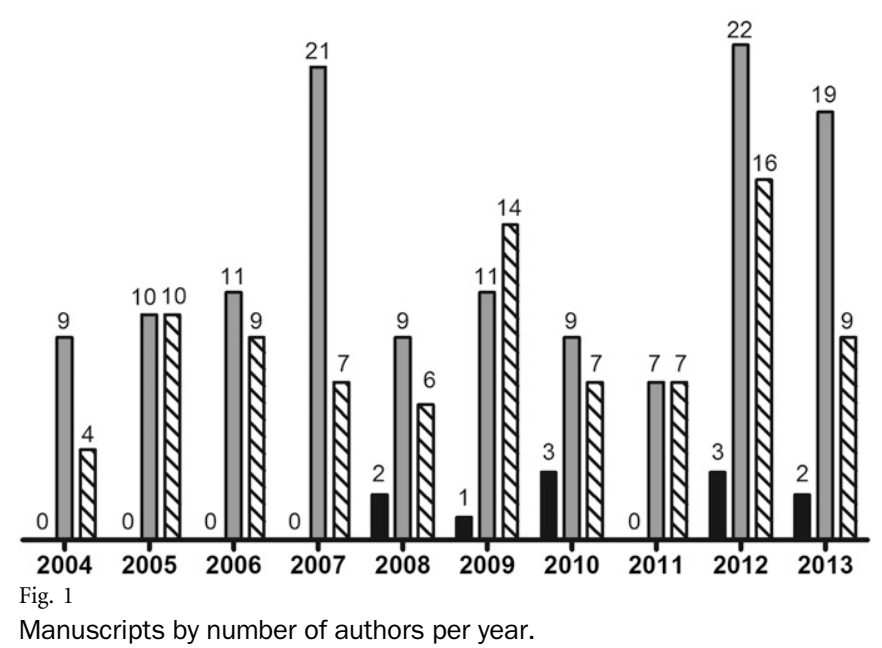


The Journal of Bone \& Joint Surgery $\cdot$ Jbjs.org Volume 97-A • Number $5 \cdot$ March 4, 2015
Characteristics of Clinical Shoulder Research in JBjS Over the Past Decade

\begin{tabular}{|lll|}
\hline \multicolumn{2}{|c|}{$\begin{array}{c}\text { TABLE V Top Ten Most-Published Combined First and Last } \\
\text { Author and Country of Origin }\end{array}$} \\
$\begin{array}{c}\text { No. of } \\
\text { Publications }\end{array}$ & \multicolumn{1}{c|}{ Author } & $\begin{array}{c}\text { Country of } \\
\text { Origin }\end{array}$ \\
\hline Fourteen & Gerber, Christian & Switzerland \\
Twelve & Matsen III, Frederick A. & United States \\
Ten & lannotti, Joseph & United States \\
Ten & Yamaguchi, Ken & United States \\
Nine & Cofield, Robert & United States \\
Eight & Robinson, C. Michael & United Kingdom \\
Seven & Frankle, Mark & United States \\
Six & Walch, Gilles & France \\
Six & Warner, Jon J.P. & United States \\
Six & Wirth, Michael & United States \\
\hline
\end{tabular}

\begin{tabular}{|c|c|}
\hline Shoulder Topic & $\begin{array}{l}\text { No. of Articles } \\
\qquad(N=228)\end{array}$ \\
\hline Rotator cuff & $64(28.1)$ \\
\hline Total shoulder arthroplasty & $43(18.9)$ \\
\hline Other & $37(16.2)$ \\
\hline Instability & $31(13.6)$ \\
\hline Reverse shoulder arthroplasty & $20(8.8)$ \\
\hline Fracture & $16(7.0)$ \\
\hline Hemiarthroplasty & $12(5.3)$ \\
\hline $\begin{array}{l}\text { Superior labral tear from anterior to } \\
\text { posterior (SLAP) or labrum }\end{array}$ & $5(2.2)$ \\
\hline
\end{tabular}

*The values are given as the number of articles, with the percentage in parentheses.

\section{Authorship}

The average number of authors per article over the last decade was 5.11. Orthopaedic literature has shown a trend toward an increase in the number of authors per article in the last sixty years ${ }^{2}$, but this trend was not significant over the last decade for JBJS shoulder articles $(\mathrm{p}=0.218)$. The average number of authors per article was lowest in 2007, at 4.68 authors, and highest in 2011, at 5.57 authors, but this was not significant. There were only eleven articles during the decade with one or two authors (Fig. 1).

We identified the first and last author from eligible clinical articles and compiled a list of all first authors, all last authors, and a combination of both first authors and last authors. We provided a top-ten list for each category (Tables III, IV, and V). Prior studies have only determined authorship on the basis of the first author only; however, this likely underreports the impact of senior authors, who are often listed as the last author ${ }^{7,12}$.
Academic Degrees of Authors and Level of Evidence

The academic degrees of the authors indicated a trend toward more nonclinician scientists and MDs with additional degrees. From 2004 to 2013, shoulder articles that included an author with an advanced research degree (MD with a $\mathrm{PhD}$ or other advanced degree) increased ( $p=0.047)$ over articles that included only clinical MDs; in the thirteen articles in 2004, there were six articles (46\%) that included an author with an advanced research degree and seven articles (54\%) that included only clinical MDs, but in the thirty articles in 2013, there were eighteen articles $(60 \%)$ that included an author with an advanced research degree and twelve articles (40\%) that included only clinical MDs.

Of the 228 studies, over the study period, the percentage of Level-I studies was $18.0 \%$ (forty-one studies), with a slight increase in Level-II studies at $18.9 \%$ (forty-three) and Level-III studies at 9.2\% (twenty-one) and a decrease in Level-IV studies at 53.9\% (123). These trends had large year-to-year variations, making the overall changes nonsignificant. Level-I, II, and III studies were more likely to have an author with an advanced research degree (MD with a PhD or other advanced degree) than were Level-IV studies, which were more likely to have authors with MDs only $(\mathrm{p}=0.03)$ (Fig. 2). Overall, the authors had an MD only (74.1\%), an MD with additional degrees (8.7\%), a $\mathrm{PhD}(6.0 \%)$, or other degrees (11.2\%).

\section{Country and Institution of Origin}

Of the 228 eligible articles, the country of origin for the articles was most commonly the United States, at 57.5\% (131 articles). European countries were the second most common countries of origin, publishing articles at $28.1 \%$ (sixty-four articles), with France contributing the largest share, at $8.3 \%$ (nineteen articles). Academic departments accounted for the majority of published articles, at 75\% (171 articles).

\section{Topics}

The most common topic was rotator cuff, at $28.1 \%$ (sixty-four articles), and the second most common topic was total shoulder arthroplasty, at $18.9 \%$ (forty-three articles) (Table VI).

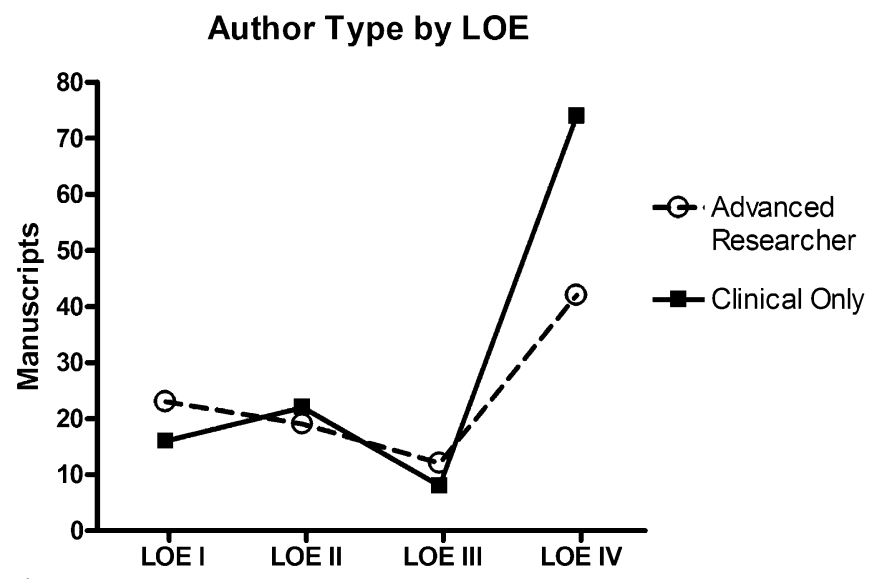

Fig. 2

Author type by level of evidence (LOE). "Advanced researcher" indicates an $\mathrm{MD}$ with a PhD or other advanced degree. "Clinical only" indicates an MD only. 


\begin{tabular}{|c|c|c|}
\hline Outcome Measurement & $\begin{array}{l}\text { No. of Articles* } \\
\quad(N=167)\end{array}$ & $\begin{array}{l}\text { Measure } \\
\text { Validation }\end{array}$ \\
\hline Constant score & $60(35.9)$ & Validated \\
\hline Simple shoulder test & $31(18.6)$ & Validated \\
\hline Visual analog scale for pain & $30(18.0)$ & Validated \\
\hline Subjective shoulder value & $16(9.6)$ & Validated \\
\hline Disabilities of the Arm, Shoulder and Hand (DASH) Outcome Measure & $15(9.0)$ & Validated \\
\hline Modified Neer score & $9(5.4)$ & Validated \\
\hline Rowe score & $8(4.8)$ & Not validated \\
\hline Western Ontario Osteoarthritis of the Shoulder Index & $3(1.8)$ & Validated \\
\hline Western Ontario Rotator Cuff Index & $3(1.8)$ & Validated \\
\hline Pain level & $3(1.8)$ & Not validated \\
\hline Short Form-12 (SF-12) Health Survey & $3(1.8)$ & Validated \\
\hline Oxford Shoulder Score & $2(1.2)$ & Validated \\
\hline Shoulder Pain and Disability Index & $2(1.2)$ & Validated \\
\hline Musculoskeletal Tumor Society score & $2(1.2)$ & Validated \\
\hline Nineteen other measurements used in only one article each & $1(0.6)$ & Varied \\
\hline
\end{tabular}

\section{Positive or Nonpositive Studies}

The majority of the studies were nonpositive studies, at $57.0 \%$ (130 articles). There was no positive-outcome publication bias over the last decade $(\mathrm{p}=0.170)$.

\section{Patient-Reported Outcome Measurements}

Overall, there was great variability of outcome measurements utilized, with at least thirty-nine different validated or nonvalidated outcome measurement tools reported in 167 eligible articles. Of these 167 articles, at least one validated patientreported outcome measurement was utilized in 139 articles $(83.2 \%)$, two validated patient-reported outcome measurements were used in fifty-one articles $(30.5 \%)$, and three or more validated patient-reported outcome measurements were used in twenty-eight articles (16.8\%). Outcome measurement tools are noted in Table VII, including the most commonly used outcome measurement tool, the Constant score, in sixty articles $(35.9 \%)$.

\section{Discussion}

Trends in shoulder research published over the last decade in JBJS have indicated an improvement in the level of evidence. Articles with a higher level of evidence were more likely to have an author with an advanced research degree. There was no positive-outcome publication bias over the last decade. Finally, there was great variability in outcome measurement instrument utilization.

\section{Level of Evidence}

In 2003, JBJS began requiring authors to provide a level of evidence rating for every clinical article, and the rating is confirmed by the editors ${ }^{8}$. The effort was introduced to help improve quality of clinical research and to allow periodic reporting of trends ${ }^{8}$. Level of evidence has been shown to be an independent predictor of acceptance for publication in JBJS. The percentage of Level-I studies in JBJS increased from $4 \%$ in 1975 to $21 \%$ in $2005^{3}$. Similarly, The American Journal of Sports Medicine had an increase in Level-I and II studies, from $9.4 \%$ in 1996 to $23.0 \%$ in $2011^{4}$. Trends for journals have indicated a shift toward an increase in the level of evidence, but it not clear whether this trend necessarily applies to orthopaedic subspecialties. The majority of clinical foot and ankle articles over the last decade from six orthopaedic journals were Level-IV studies (70.1\%), with only $9.4 \%$ Level-I studies ${ }^{13}$.

Our data indicated a high percentage of Level-I shoulder studies (18.1\%) over the last decade in JBJS, which is consistent 
The Journal of Bone \& Joint Surgery $\cdot$ Jbjs.org Volume 97-A - Number $5 \cdot$ March 4, 2015
Characteristics of Clinical Shoulder Research in JBjS

Over the Past Decade with the recent improvements seen with the number of published Level-I studies among all orthopaedic topics in JBJS as well as the recent increased emphasis on evidence-based medicine $^{3}$. The percentage of Level-I shoulder studies was also higher than the percentage reported in foot and ankle articles ${ }^{13}$. There was a higher percentage of shoulder publications with Level-I and II evidence (37.1\%) than in the recently reported data for The American Journal of Sports Medicine publications ${ }^{4}$. To our knowledge, there have been no prior orthopaedic studies showing a correlation between authors with advanced research degrees and an improvement in the level of evidence.

\section{Authorship}

Orthopaedic literature has shown a trend toward increased authorship $^{2}$, but our data indicated that this trend has not continued over the last decade in JBJS shoulder articles. Authorship has been labeled as the currency of academic medicine and is used as a way to improve admission to medical school and residency, to obtain research grants, and to gain promotion $^{2}$. Some believe that the increase in authorship, especially the addition of physicians with advanced degrees and nonphysician scientists, may indicate an improvement in the complexity of research questions and study design ${ }^{2}$.

\section{Positive or Nonpositive Outcome}

There is a discrepancy regarding positive-outcome publication bias in orthopaedics. A study analyzing 1181 manuscripts submitted for publication to JBJS reported no evidence for publication bias'. Positive and nonpositive studies were accepted at similar rates ${ }^{9}$. However, a separate study found that 210 peer reviewers for JBJS and Clinical Orthopaedics and Related Research were more likely to recommend publication of a positive version of a fabricated manuscript over an otherwise identical nodifference version ${ }^{5}$. Our data did not find a positive-outcome publication bias in JBJS shoulder articles over the last decade, and the majority of the studies represented nonpositive outcomes.

\section{Most-Cited Articles, Top Authors, and Topics}

We utilized both Thomson Reuters Web of Science and Google Scholar to determine the number of citations for each article. Thomson Reuters Web of Science is a proprietary product, but Google Scholar is free. There are critiques of both search tools, with no clear better tool for determination of citations ${ }^{14}$. Web of Science has been widely utilized in the orthopaedic literature to determine the number of citations ${ }^{7,12,15,16}$. Web of Science reported approximately half the number of citations per article compared with Google Scholar in our search; however, both search tools matched on nine of the top ten most-cited articles. Ultimately, both search engines only determine the number of times that an article is cited, which does not necessarily determine the true impact or merit of each individual article.

We highlighted the most-cited shoulder articles and the most-published first and last authors in the last decade in JBJS. There have been several recent publications highlighting similar compilations based on the most-cited articles across mul- tiple orthopaedic journals for pediatrics, trauma, hand, and shoulder ${ }^{7,12,15,16}$. The number of citations and the number of publications alone do not completely account for the impact or merits of individual researchers.

The most common shoulder topics in the last decade, rotator cuff and shoulder arthroplasty, were not surprising, especially with growing interest and research regarding reverse shoulder arthroplasty since its approval by the United States Food and Drug Administration (FDA) in 2003. An awareness of shoulder topics published may help to identify areas in which deficiencies exist and growth is needed.

\section{Country of Origin}

A recent study showed an increase in publications from outside of the United States in The American Journal of Sports Medicine, from $20.3 \%$ in 1996 to $53.0 \%$ in $2011^{4}$. Similarly, the number of publications from outside of the United States increased from $40.5 \%$ in 1949 to $59.6 \%$ in 2009 in JBJS $^{2}$.

\section{Patient-Reported Outcome Measurements}

There has been an increase in utilization of patient-reported outcome measurements in orthopaedics, but there continues to be considerable inconsistency in the application of these outcome tools ${ }^{13}$. A study analyzing 878 clinical foot and ankle articles from six orthopaedic journals from 2002 to 2011 showed that 139 unique clinical outcome measurements were used ${ }^{13}$. Our data indicated great variability in the outcome measurements utilized in shoulder articles over the last decade in JBJS. A consensus is needed in shoulder research regarding outcome measurement tool utilization.

\section{Strengths and Limitations}

It is possible that important articles were inadvertently omitted or were not identified in our original search. Our strict inclusion and exclusion criteria established a priori may have excluded important shoulder-related articles, including cadaveric, computer-modeling and simulation, and basic science studies. It is also possible that we may have missed some of the trends that occurred one to two decades prior to our study period. Another potential limitation is the classification of academic compared with private. There are private practices that participate in resident and fellowship training. For the purposes of this study, we limited the academic distinction to institutions that lead a residency training program. Furthermore, highlighting articles by the number of citations can be misleading, as authors or institutions may frequently cite their own articles, causing inflation in the number of citations. Another limitation of the study was that only JBJS articles were evaluated and the study may not reflect the overall trends in publications of shoulder research in other journals. The American Journal of Sports Medicine and Arthroscopy: The Journal of Arthroscopic and Related Surgery, among others, also publish shoulder research but do not usually include shoulder arthroplasty or fracture topics. The Journal of Shoulder and Elbow Surgery is a shoulder subspecialty journal that may also have a different focus than JBJS has. 
The Journal of Bone \& Joint Surgery - JBjs.org Volume 97-A • Number $5 \cdot$ March 4, 2015
Characteristics of Clinical Shoulder Research in JBJS

Over the Past Decade
In conclusion, overall trends in clinical shoulder surgery publications over the last decade in JBJS indicate an improvement in the level of evidence corresponding to recent increased emphasis on evidence-based medicine. Articles with a higher level of evidence were more likely to have an author with an advanced research degree, reflecting the complexities of this type of research. A consensus is needed in shoulder research for more consistent application of validated patient-reported outcome measurement tools.

Gary M. Gartsman, MD

Hussein A. Elkousy, MD

T. Bradley Edwards, MD

Fondren Orthopedic Group,

Texas Orthopedic Hospital,

7401 South Main Street,
Houston, TX 77030.

E-mail address for G.M. Gartsman: ggartsman@g9md.net

Brent J. Morris, MD

Lexington Clinic Orthopedics,

Shoulder Center of Kentucky,

700 Bob-O-Link Drive,

Lexington, KY 40504

\section{R. Zackary Unger, MD}

Department of Orthopaedic Surgery and Sports Medicine,

University of Kentucky, Kentucky Clinic,

740 South Limestone Street, Suite 401,

Lexington, KY 40536-0284

Mitzi S. Laughlin, $\mathrm{PhD}$

Health and Human Performance,

University of Houston,

3855 Holman Street,

Garrison Room 104,

Houston, TX 77204-6015

\section{References}

1. Tornetta P 3rd, Siegel J, McKay P, Bhandari M. Authorship and ethical considerations in the conduct of observational studies. J Bone Joint Surg Am. 2009 May;91 (Suppl 3):61-7.

2. Camp M, Escott BG. Authorship proliferation in the orthopaedic literature. J Bone Joint Surg Am. 2013 Apr 3;95(7):e44.

3. Hanzlik S, Mahabir RC, Baynosa RC, Khiabani KT. Levels of evidence in research published in The Journal of Bone and Joint Surgery (American Volume) over the last thirty years. J Bone Joint Surg Am. 2009 Feb;91(2):425-8.

4. Cvetanovich GL, Fillingham YA, Harris JD, Erickson BJ, Verma NN, Bach BR Jr. Publication and level of evidence trends in The American Journal of Sports Medicine from 1996 to 2011. Am J Sports Med. 2014 Apr 10. [Epub ahead of print]

5. Emerson GB, Warme WJ, Wolf FM, Heckman JD, Brand RA, Leopold SS. Testing for the presence of positive-outcome bias in peer review: a randomized controlled trial. Arch Intern Med. 2010 Nov 22;170(21):1934-9.

6. Hasenboehler EA, Choudhry IK, Newman JT, Smith WR, Ziran BH, Stahel PF. Bias towards publishing positive results in orthopedic and general surgery: a patient safety issue? Patient Saf Surg. 2007 Nov 27;1(1):4.

7. Kavanagh RG, Kelly JC, Kelly PM, Moore DP. The 100 classic papers of pediatric orthopaedic surgery: a bibliometric analysis. J Bone Joint Surg Am. 2013 Sep 18; 95(18):e134.

8. Wright JG, Swiontkowski MF, Heckman JD. Introducing levels of evidence to the journal. J Bone Joint Surg Am. 2003 Jan;85(1):1-3.

9. Okike K, Kocher MS, Mehlman CT, Heckman JD, Bhandari M. Publication bias in orthopaedic research: an analysis of scientific factors associated with publication in The Journal of Bone and Joint Surgery (American Volume). J Bone Joint Surg Am. 2008 Mar;90(3):595-601.

10. Wright RW, Baumgarten KM. Shoulder outcomes measures. J Am Acad Orthop Surg. 2010 Jul;18(7):436-44.

11. Galatz LM, Ball CM, Teefey SA, Middleton WD, Yamaguchi K. The outcome and repair integrity of completely arthroscopically repaired large and massive rotator cuff tears. J Bone Joint Surg Am. 2004 Feb;86(2):219-24.

12. Lefaivre KA, Guy P, O'Brien PJ, Blachut PA, Shadgan B, Broekhuyse HM. Leading 20 at 20: top cited articles and authors in the Journal of Orthopaedic Trauma, 19872007. J Orthop Trauma. 2010 Jan;24(1):53-8.

13. Hunt KJ, Hurwit D. Use of patient-reported outcome measures in foot and ankle research. J Bone Joint Surg Am. 2013 Aug 21;95(16):e118:1-9.

14. Bakkalbasi N, Bauer K, Glover J, Wang L. Three options for citation tracking: Google Scholar, Scopus and Web of Science. Biomed Digit Libr. 2006 Jun 29:3:7.
15. To $P$, Atkinson CT, Lee DH, Pappas ND. The most cited articles in hand surgery over the past 20-plus years: a modern-day reading list. J Hand Surg Am. 2013 May;38(5):983-7. Epub 2013 Apr 3

16. Namdari S, Baldwin K, Kovatch K, Huffman GR, Glaser D. Fifty most cited articles in orthopedic shoulder surgery. J Shoulder Elbow Surg. 2012 Dec;21(12): 1796-802. Epub 2012 Apr 7.

17. Boileau P, Brassart N, Watkinson DJ, Carles M, Hatzidakis AM, Krishnan SG Arthroscopic repair of full-thickness tears of the supraspinatus: does the tendon really heal? J Bone Joint Surg Am. 2005 Jun;87(6):1229-40.

18. Werner CM, Steinmann PA, Gilbart M, Gerber $C$. Treatment of painful pseudoparesis due to irreparable rotator cuff dysfunction with the Delta III reverse-ball-andsocket total shoulder prosthesis. J Bone Joint Surg Am. 2005 Jul;87(7):1476-86.

19. Teefey SA, Rubin DA, Middleton WD, Hildebolt CF, Leibold RA, Yamaguchi K. Detection and quantification of rotator cuff tears. Comparison of ultrasonographic, magnetic resonance imaging, and arthroscopic findings in seventy-one consecutive cases. J Bone Joint Surg Am. 2004 Apr;86(4):708-16.

20. Boileau $P$, Villalba M, Héry JY, Balg F, Ahrens $P$, Neyton L. Risk factors for recurrence of shoulder instability after arthroscopic Bankart repair. J Bone Joint Surg Am. 2006 Aug;88(8):1755-63.

21. Frankle M, Levy JC, Pupello D, Siegal S, Saleem A, Mighell M, Vasey M. The reverse shoulder prosthesis for glenohumeral arthritis associated with severe rotator cuff deficiency. a minimum two-year follow-up study of sixty patients. J Bone Joint Surg Am. 2005 Aug;87(8):1695-705.

22. Yamaguchi K, Ditsios K, Middleton WD, Hildebolt CF, Galatz LM, Teefey SA. The demographic and morphological features of rotator cuff disease. A comparison of asymptomatic and symptomatic shoulders. J Bone Joint Surg Am. 2006 Aug; 88(8):1699-704.

23. Sugaya $\mathrm{H}$, Maeda $\mathrm{K}$, Matsuki $\mathrm{K}$, Moriishi J. Repair integrity and functional outcome after arthroscopic double-row rotator cuff repair. A prospective outcome study. J Bone Joint Surg Am. 2007 May;89(5):953-60.

24. Wall B, Nové-Josserand L, O'Connor DP, Edwards TB, Walch G. Reverse total shoulder arthroplasty: a review of results according to etiology. J Bone Joint Surg Am. 2007 Jul;89(7):1476-85.

25. Guery J, Favard L, Siriveaux F, Oudet D, Mole D, Walch G. Reverse total shoulder arthroplasty. Survivorship analysis of eighty replacements followed for five to ten years. J Bone Joint Surg Am. 2006 Aug;88(8):1742-7.

26. Gerber $C$, Maquieira G, Espinosa N. Latissimus dorsi transfer for the treatment of irreparable rotator cuff tears. J Bone Joint Surg Am. 2006 Jan;88(1):113-20. 